\title{
ENSINO DE MATEMÁTICA NOS ANOS INICIAIS: TRANSFORMANDO PRÁTICAS PEDAGÓGICAS
}

\author{
MATHEMATICS TEACHING IN ELEMENTARY SCHOOL: \\ TRANSFORMING PEDAGOGICAL PRACTICES \\ DANIELA GUSE 1 \\ EVERALDO SILVEIRA ${ }^{2}$
}

\section{RESUMO}

Este texto é baseado no resultado de uma pesquisa de mestrado desenvolvida na Rede Municipal de Ensino de Florianópolis, no ano de 2017, na qual procuramos identificar como a formação continuada do Pacto Nacional pela Alfabetização na Idade Certa (PNAIC) poderia ter influenciado as práticas pedagógicas no ensino de matemática. 0 PNAIC foi um programa do governo federal do Brasil, em parceria com universidades públicas e secretarias de educação municipais e estaduais, executado entre 2012 e 2018 e uma de suas ações era a formação continuada de professores alfabetizadores. Para a realização da pesquisa utilizou-se a metodologia Grounded Theory, por meio da qual construímos uma compreensão sobre o processo de formação e suas influências nas práticas dos participantes aplicando instrumentos como questionários e entrevistas. Foi possível identificar algumas transformações nas práticas pedagógicas relatadas pelos docentes, bem como a influência da formação continuada como subsídio para essas mudanças e novas aprendizagens.

Palavras-chave: Educação de matemática. Anos iniciais. Formação continuada. PNAIC. Grounded Theory.

\section{ABSTRACT}

This paper is based on results of a research developed in Florianópolis' Municipal Education Network, at 2017, which tried to show how the National Pact for Literacy at the Right Age's (NPLRA) continuing education could have influenced pedagogical practices in mathematics teaching. NPLRA was a federal government program, in partnership with public universities and municipal and state education departments, between 2012 and 2018, and one of its actions was the continuing education of literacy teachers. For this research it was used the Grounded Theory methodology, creating a comprehension about this education process and its influences around day by day teachers' practices who applied instruments such as questionnaires and interviews. So, it was possible to make clear some transformations that occurred in pedagogic practices which had been reported by teachers and what was the influence of the continuing education as a subsidy for these changes and new learning.

Keywords: Mathematics Teaching. Elementary School. Continuing Education. NPLRA. Grounded Theory.

\footnotetext{
1 Mestra em Educação Científica e Tecnológica pela Universidade Federal de Santa Catarina PPGECT/UFSC. Professora na Secretaria Municipal de Educação de Florianópolis. E-mail: daniguse.floripa@gmail.com. Orcid: https://orcid.org/0000-0002-7131-9209

2 Doutor em Educação Científica e Tecnológica (UFSC). Universidade Federal de Santa Catarina. E-mail: derelst@hotmail.com. Orcid: https:// orcid.org/0000-0002-2113-2227
} 


\section{INTRODUÇÃO}

Para compreendermos como a formação continuada do Pacto Nacional pela Alfabetização na Idade Certa pode ter influenciado transformações nas práticas pedagógicas de professores que ensinam matemática é preciso conhecer algumas características desse programa denominado PNAIC. Ele foi desenvolvido pelo Governo Federal do Brasil, por meio do Ministério da Educação - MEC, em parceria com estados, municípios e universidades públicas, conforme detalhamento a seguir:

0 PNAIC - Pacto Nacional pela Alfabetização na Idade Certa é um compromisso formal e solidário assumido pelos governos Federal, do Distrito Federal, dos Estados e dos Municípios, desde 2012, para atender à Meta 5 do Plano Nacional da Educação (PNE), que estabelece a obrigatoriedade de Alfabetizar todas as crianças, no máximo, até o final do $3^{0}$ (terceiro) ano do ensino fundamental. (BRASIL, 2017, p. 3) [...]

Por meio do PNAIC milhares de professores alfabetizadores de todo o Brasil tiveram a oportunidade de dar continuidade aos seus estudos de aperfeiçoamento e,

de acordo com dados disponíveis no Sistema Informatizado de Monitoramento do PNAIC (SisPacto), em 2013, foram capacitados, em Linguagem, 313.599 professores alfabetizadores em curso com carga horária de 120 horas; em 2014, foram 311.916 profissionais e a ênfase da formação foi em Matemática, em curso com carga horária de 160 horas; em 2015, foram capacitados 302.057 professores em temáticas como Gestão Escolar, Currículo, a Criança do Ciclo de Alfabetização e Interdisciplinaridade; e, em 2016, foram 248.919 alfabetizadores e 38.598 coordenadores pedagógicos atendidos em cursos com carga horária mínima de 100 horas e com ênfase em leitura, escrita e letramento matemático. (BRASIL, 2017, p. 3-4)

Neste trabalho, especificamente, investigamos aspectos da formação continuada em serviço, desenvolvida no ano 2014, com foco em Alfabetização Matemática. Naquele ano a formação continuada do PNAIC desenvolveu-se dentro de uma

estrutura composta, inicialmente, por dois grupos de professores: os formadores e os orientadores de estudo. A ação destes incide sobre um terceiro grupo, o dos Professores Alfabetizadores, que trabalha diretamente com as crianças que são 0 objetivo maior do programa. 0 Professor Formador, profissional selecionado por universidades públicas brasileiras, realiza a formação dos Orientadores de Estudo. 0 Orientador de Estudos, por sua vez, selecionado pelos municípios a partir de critérios estabelecidos pelo MEC, organiza, com base nos mesmos princípios formativos, a formação dos Professores Alfabetizadores, atuantes nos três primeiros anos, em escolas públicas de diversas regiões do País. (BRASIL, 2014, p. 11)

No caso da Rede Municipal de Ensino de Florianópolis (RMEF), onde a pesquisa foi realizada, a Universidade Federal de Santa Catarina - UFSC coordenou a formação pedagógica dos orientadores de estudo que, por sua vez, realizaram a formação dos professores alfabetizadores com uma proposta de estudos em grupos daqueles profissionais que trabalhavam com o mesmo ano escolar. Os temas apresentados, relacionados aos conhecimentos matemáticos a serem desenvolvidos com as 
crianças, eram discutidos entre pares, os quais eram orientados a criar e colocar em prática propostas de trabalho embasadas nos temas abordados nos encontros. Depois os professores relatavam como isso ocorrera, refletiam coletivamente acerca disso e pensavam na superação de possíveis obstáculos metodológicos surgidos nos diversos contextos de trabalho com as crianças do ciclo de alfabetização. A participação em cursos de formação continuada entre pares que compartilham certos conhecimentos, práticas e dificuldades aproximadas mostrou ser uma oportunidade de superação de certos obstáculos do cotidiano a partir da ampliação e do aprofundamento de conhecimentos teóricos e metodológicos e da reflexão sobre as próprias atividades individuais e coletivas. Redimensionar significativamente o próprio fazer pedagógico para a qualificação da Alfabetização Matemática, de acordo com as demandas e possibilidades de cada professor, é uma necessidade individual no âmbito de sua sala de aula e de sua turma de alunos; e coletiva, no âmbito do diálogo e da colaboração entre colegas. Nesta perspectiva, a formação realizada com os professores alfabetizadores corrobora a afirmação de Paulo Freire sobre a importância da reflexão sobre a prática:

[...] na formação permanente dos professores, 0 momento fundamental é o da reflexão crítica sobre a prática. É pensando criticamente a prática de hoje ou de ontem que se pode melhorar a próxima prática. 0 próprio discurso teórico, necessário à reflexão prática, tem de ser de tal modo concreto que quase se confunda com a prática. (FREIRE, 1996, p. 39)

Devemos ressaltar que a proposta de formação desenvolvida é a de Alfabetização Matemática na perspectiva do Letramento, um pressuposto adotado em consonância com 0 material de formação em linguagem. Dessa forma, a Alfabetização Matemática abordada no PNAIC tem a concepção de uma linguagem necessária para a leitura do mundo, uma perspectiva que supera a simples decodificação dos números e a resolução das quatro operações básicas. Considerando essa concepção, materializamos neste estudo a compreensão de possíveis transformações nas práticas de ensino de matemática por professores pedagogos alfabetizadores. Temos claro que a melhoria do desempenho escolar das crianças na aprendizagem matemática depende de múltiplos fatores e ações diversificadas de muitas frentes: pedagógicas, sociológicas, econômicas, biológicas, psicológicas, políticas e outras. Mas, também entendemos que a qualificação da ação docente é de suma importância para colaborar nesse processo, pois a ação pedagógica é a instância social formal de ensino e aprendizagem.

\section{METODOLOGIA DA PESQUISA}

Para compreender a relação entre a formação continuada do professor alfabetizador e a sua atividade pedagógica, optamos pela busca de dados descritivos que representassem a visão dos participantes acerca desse processo. Sendo assim, desenvolvemos um estudo exploratório, identificando os-aspectos que permeiam o contexto da formação continuada de professores alfabetizadores, no âmbito do PNAIC, trazendo à tona as expressões dos professores participantes acerca das relações que eles percebem entre a formação e sua atuação pedagógica. Segundo Gil (2010, p. 27), um estudo exploratório tem como propósito proporcionar maior familiaridade com o problema, tornando-o mais explícito. Este estudo exploratório teve um caráter qualitativo, uma vez que analisamos o problema a partir da compreensão do processo e das manifestações dos sujeitos 
que dele fizeram parte. Ludke e André (1986) consideram a tentativa de capturar a perspectiva dos participantes, uma das características da pesquisa qualitativa, como se vê na seguinte afirmação:

Nesses estudos há sempre uma tentativa de capturar a perspectiva dos participantes, isto é, a maneira como os informantes encaram as questões que estão sendo focalizadas. Ao considerar os diferentes pontos de vista dos participantes, os estudos qualitativos permitem iluminar o dinamismo interno das situações, geralmente inacessível ao observador externo. (LUDKE E ANDRÉ, 1986, p. 12)

Tendo como orientação essa abordagem exploratória e qualitativa, iniciamos o processo de busca dos dados, por meio de questionários e entrevistas, seguindo-se a metodologia da Grounded Theory (GT). Segundo Tarozzi (2011, p. 19), o êxito de uma pesquisa conduzida com a Grounded Theory (GT) é a construção de uma teoria, com uma interpretação racional, articulada e sistemática, capaz de representar a realidade estudada. 0 objetivo é trazer à tona a teoria imbricada nos fatos empíricos observados, de modo que a teoria produzida tenha uma sólida base empírica, ou seja, extraída a partir dos dados. 0 processo de produção de uma Grounded Theory não é linear e é definido após uma imersão preliminar no campo de pesquisa, onde os dados são produzidos na interação entre o pesquisador e os participantes, permitindo que o pesquisador possa retornar aos dados e ao campo sempre que precisar aprofundar suas compreensões sobre o fenômeno estudado. Nesse processo, a coleta de dados e a amostragem podem ir se ampliando e os instrumentos de coleta de dados podem passar de um formato semiestruturado para outros cada vez mais estruturados e focalizados. Como veremos a seguir, isso aconteceu quando elaboramos o primeiro questionário baseado no pressuposto de que os participantes poderiam analisar e avaliar se o curso de formação continuada em questão havia contribuído para seu aperfeiçoamento profissional, no sentido de aprimorar e transformar algumas práticas pedagógicas para 0 ensino de matemática. Depois de analisar as respostas das professoras entrevistadas, percebemos que faltavam informações específicas sobre os tipos de mudanças possivelmente ocorridas. Isso não se configurou em um problema já que a GT possibilita, tanto quantas voltas forem necessárias ao campo de pesquisa, quanto o aprimoramento dos instrumentos de coleta de dados. Assim, elaboramos e aplicamos um segundo questionário com 0 intuito de aprofundar algumas questões cujas respostas não trouxeram as informações esperadas no primeiro.

No início do processo de coleta de dados, em 2017, fizemos a primeira abordagem aos professores alfabetizadores solicitando que respondessem um questionário impresso cujo objetivo principal seria levantar as primeiras informações sobre o perfil profissional dos professores e seu exercício laboral, além de identificar aqueles que participaram do curso do PNAIC em 2014. Por meio desse questionário alcançamos os professores que estavam presentes no primeiro dia da formação em 2017. Tínhamos a estimativa de atingir cerca de duzentos participantes do $1^{0}$ ao $5^{\circ}$ ano do ensino fundamental para, inicialmente, identificar aqueles que participaram da formação do PNAIC/2014, inclusive os que poderiam estar trabalhando fora do ciclo de alfabetização, ou seja, com turmas de $4^{0}$ ou $5^{0}$ ano. Definir professores nessa situação e poder entrevistá-los poderia trazer para a pesquisa resultados muito ricos no sentido de saber se os conhecimentos abordados na formação para o ciclo de alfabetização foram apropriados por estes sujeitos e, caso estivessem utilizando-os em turmas mais avançadas, indicaria que conseguiram não só se apropriar deles, mas também de adaptá-los às novas situações, corroborando a ideia de que programas de formação continuada podem influenciar a docência e contribuir para a qualificação de atividades de ensino. 
Os questionários foram identificados com os nomes e contatos dos professores, pois isso é que nos permitiria ter acesso aos mesmos participantes para a realização de posteriores entrevistas. E como prevêem as determinações éticas, na análise dos dados, os participantes não foram identificados pelos nomes e sim por pseudônimos.

Recebemos a devolução de 94 questionários respondidos parcial ou integralmente, com os quais foi possível delinear o perfil de um grupo de professores de anos iniciais que trabalhavam na Rede Municipal de Ensino de Florianópolis em 2017. Para identificar cada professor/participante da pesquisa, definimos um pseudônimo que indicava 0 ano escolar em que atuava e um número sequencial correspondente ao número de participantes de cada ano escolar. Então, todos começavam com a letra P que indicava professor. Logo em seguida um número que indica 0 ano em que atuava. $E$ à direita do ponto, outro número indicava uma localização dentro do grupo. Por exemplo: P1.1 (Professor do $1^{0}$ ano. Prof.1).

Dentre os respondentes dos 94 questionários, identificamos 48 professores que haviam participado do curso do PNAIC com foco em alfabetização matemática em 2014. Desses, 25 manifestaram no questionário concordância em serem procurados para concederem entrevista. 0 contato com estes professores foi realizado por meio de e-mail, solicitando 0 agendamento de um encontro para a realização da mesma. Três professoras deram retorno: P3.3, P1.1 e P3.4.

Os resultados destes questionários geraram as primeiras informações da pesquisa, sendo assim considerados documentos primários na metodologia Grounded Theory. As primeiras codificações geradas, identificam as unidades mínimas de significado (TAROZZI, 2011, p. 70) que se manifestam de forma recorrente nas respostas dos diferentes participantes através de uma análise palavra por palavra, linha por linha e acontecimento por acontecimento.

[...] a codificação acontece em três fases progressivas e, conceitualmente, cada vez mais elevadas. A primeira, codificação inicial, explora analiticamente os dados, abrindo-os a todas as direções possíveis, indagando pontualmente e meticulosamente cada porção do texto de que são constituídos e designando as primeiras etiquetas conceituais. A segunda, por um lado, analisa elementos conceituais comuns subjacentes a porções mais amplas de texto e, por outro lado, organiza e sintetiza os dados esboçando as categorias e reunindo-as em macrocategorias. [...] a terceira fase, enfim, é o momento da construção da teoria. Quando as categorias estão maduras, evidenciam-se os nexos que as interligam e, sobretudo, são integradas dentro de uma teoria coerente e unitária. (TAROZZI, 2011, p. 122-123)

A partir dessas entrevistas, identificamos várias unidades de sentido emergentes e as organizamos em cinco categorias que, em nosso entendimento, agrupam elementos conceituais comuns em sua natureza prática e demonstram como agregam as contribuições da formação continuada na pedagogia dos professores: 1.Importância da formação; 2.Aprendizagens a partir da formação; 3.Recursos, materiais e estratégias; 4.Estrutura metodológica da formação e 5.Condições de trabalho.

Percebendo a necessidade de aprofundar a compreensão sobre essas categorias, elaboramos uma nova entrevista, dessa vez, numa abordagem mais reflexiva, com questões mais direcionadas aos conteúdos trabalhados durante os encontros de estudo, procurando identificar os conhecimentos e as condições necessárias para possíveis transformações nas ações desses professores.

Como mencionamos anteriormente, a GT é uma metodologia que prevê o retorno ao campo de pesquisa sempre que o pesquisador precisar ampliar ou aprofundar informações até que haja 
uma saturação teórica (TAROZZI, 2011). Logo, nessa etapa, optamos por uma abordagem reflexiva da entrevista porque entendemos que seria importante garantir que a compreensão do pesquisador fosse fidedigna ao que 0 entrevistado tinha a dizer. Dessa forma, 0 entrevistador pode ir devolvendo ao participante uma síntese do que compreendeu a partir de sua fala, oportunizando uma reelaboração de suas colocações anteriores ou a confirmação de sua declaração (SZYMANSKI, 2004). Nessa etapa, foram realizadas cinco entrevistas (P1.1, P1.3, P2.6, P3.1 e P3.4) cujas informações possibilitaram um aprofundamento teórico para cada categoria estabelecida. De acordo com Tarozzi (2011, p. 163), na metodologia da Grounded Theory, as conclusões precisam dar conta de como os resultados emersos da pesquisa podem dizer algo de concreto e, para a discussão dos resultados, buscam-se conhecimentos sobre o tema através da revisão bibliográfica, que vai sendo definida e aprofundada durante o processo de codificação, de acordo com a emersão dos dados.

A partir das categorias emersas dos dados, no processo analítico inicial, passamos ao processo sintético de identificação das ligações entre os dados para a construção de uma compreensão coerente sobre o tema investigado.

No próximo tópico apresentaremos cada uma das categorias fundamentando-as teoricamente, na intenção de demonstrar como o curso de formação continuada do PNAIC influenciou de alguma forma as atividades de ensino de muitos docentes, contribuindo para sua qualificação profissional.

\section{REFLEXÕES, PRÁTICAS E TRANSFORMAÇÕES PEDAGÓGICAS}

\section{A IMPORTÂNCIA DA FORMAÇÃO}

Para questionar sobre as motivações e as principais contribuições da formação continuada de maneira geral, na perspectiva dos professores, apresentamos aos participantes a seguinte questão:

Em sua opinião, qual a principal contribuição dos cursos de formação continuada?

( ) promoção na carreira ( ) aprofundamento teórico ( ) conhecimento sobre práticas de ensino ( ) interação entre colegas ( ) possibilidade de refletir sobre a própria prática pedagógica ( ) outra. Qual? (WEBER, 2018, p. 91)

Constatamos que as motivações mais citadas pelos professores para participarem de cursos de formação continuada são: 1) A possibilidade de reflexão sobre a própria prática e 2) A busca de conhecimentos sobre práticas de ensino.

Essas duas contribuições ficam evidentes por meio de comentários de alguns participantes quando questionados se a formação continuada do PNAIC-2014, sobre Alfabetização Matemática, contribuiu para a qualificação e transformação de sua prática pedagógica, como podemos ver a seguir:

Estudar, repensar, analisar sempre acrescenta e amplia conhecimentos para nossa prática. Fazer as atividades do PNAIC e aplicar nas turmas faz com que reflitamos e aprendamos mais. (P3.3)

Ajudou muito. Porque eu tinha resistência em alguns conteúdos para ensinar, pois não havia compreensão sobre os mesmos, e com as leituras e explicações do curso ficou mais tranquilo compreender. (P3.4)

Sim, para repensar as práticas pedagógicas e aplicar novos conhecimentos. (P1.26) 
Aprendi novas possibilidades para apresentar determinados conteúdos matemáticos. (P1.12)

A formação continuada faz toda diferença na minha atuação. Para repensar minhas práticas, as trocas de experiências entre colegas e formadores são fundamentais. (P1.8) Consegui rever conceitos e mudar algumas práticas, principalmente na ampliação dos conceitos sobre gráficos e temporalidade. (P1.10) (WEBER, 2018, p. 92)

Um ponto importante a ressaltar é que os professores/participantes mostraram valorizar atividades práticas que podem ser levadas para sua realidade e perceber que isso contribui para 0 desenvolvimento de sua própria compreensão sobre 0 conteúdo e para a reflexão sobre sua própria ação docente. Nesse sentido, Curi (2013) citada por Justo e Dorneles (2012, p. 92) afirma que uma melhoria nos conhecimentos matemáticos, didáticos e curriculares ocorre "[...] quando professores participam de processos de formação que possibilitam reflexões, relações entre teoria, prática e pesquisa e proporcionam análises e planejamento de atividades em que esses conhecimentos são utilizados em sua prática no ensino".

A possibilidade de oportunizar aos professores em formação continuada a realização de atividades aplicáveis para o dia-a-dia pode ser uma das principais motivações para 0 desejo de aprendizagem e transformação da prática pedagógica por parte desses sujeitos. Segundo Monteiro e Giovanni (2000, p. 139-140) a realização de atividades práticas, oficinas e workshops tem como principal contribuiçãa: "[...] o fato de que é nesse momento que os fundamentos teóricos podem ser retomados, vivenciando-se um processo que, devidamente adaptado pelos professores participantes, poderá ser realizado por eles, com seus próprios alunos". Ainda segundo Monteiro e Giovanni (2000) esses momentos de vivência geram entusiasmo e envolvimento que motivam o professor a aplicar tais atividades. Mas é preciso estar claro que o PNAIC não preconizava a prática pela prática e, sim, a vivência e a reflexão sobre ela. Os professores eram instigados a usarem, em suas turmas, atividades e conceitos trabalhados na formação e solicitados a apresentarem relatos disso. A partir daí procurava-se compreender o contexto, as dificuldades e as possibilidades por meio de análise coletiva dos relatos. Para Alarcão (2011), a análise de casos reais é uma estratégia de grande valor formativo, pela qual é possível vislumbrar situações complexas, construir conhecimentos e/ou tomar consciência daquilo que já se sabia.

Se a preocupação do professor é que a teoria Ihe dê condições de resolver problemas cotidianos da docência, faz-se necessário que se reflita sobre essa integração, ou seja, sobre sua práxis. Para tanto, é preciso que haja tempos e espaços pedagógicos em que ocorram esses estudos, práticas e reflexões. A formação continuada em serviço pode ser uma possibilidade. Pimenta (2009) indica que durante a preparação do professor, mesmo em fase inicial, a prática pedagógica deve ser tomada como objeto de análise para a ressignificação dos processos formativos.

No que se refere à formação contínua, a prática mais frequente tem sido a de realizar cursos de suplência e/ou atualização dos conteúdos de ensino. Esses programas têm se mostrado pouco eficientes para alterar a prática docente e, consequentemente, as situações de fracasso escolar, por não tomarem a prática docente e pedagógica escolar nos seus contextos. Ao não as colocar como o ponto de partida e 0 de chegada da formação, acabam por, tão somente, ilustrar individualmente 0 professor, não lhe possibilitando articular e traduzir os novos saberes em novas práticas (FUSARI, 1988 apud PIMENTA, 2009, p. 16). 
Na formação continuada, então, essa análise e reflexão ganha ainda mais sentido, pois os professores já estão em atividade e envolvidos com as necessidades cotidianas que sua prática de ensino lhes exige em situações reais. Segundo os participantes entrevistados, uma importante contribuição do PNAIC em Alfabetização Matemática, foi trazer uma legitimidade para certas práticas, tais como 0 uso de jogos em sala de aula e o incentivo aos registros pessoais de cada criança para representar suas estratégias de pensamento matemático, dentre outras. Isso se manifesta na fala desta professora, por exemplo:

0 PNAIC me deu essa segurança de aceitar a resposta da criança, o jeito como ela consegue construir, trabalhar e inovar em cima disso também. Mas em algumas escolas não aceitavam isso... Hoje eu aceito muito mais o registro de como ele (0 aluno) buscou a resposta, do que propriamente uma resposta. Só a resposta pela resposta não me satisfaz. Antes do PNAIC eu dava mais valor para 0 algoritmo. Hoje eu procuro entender como 0 aluno pensa. (P2.6) (WEBER, 2018, p. 114)

Em outro diálogo, percebemos novamente 0 receio da professora com relação à sua própria prática e a necessidade da legitimidade que o curso lhe confere, simbolicamente validando sua ação com relação aos modos de registros pessoais da criança para a resolução de problemas.

P2.6: [...] A gente não tinha abertura para ampliar e parecia que o desenho não significava nada. Significa! A forma de representar uma resposta... Pesquisadora: E essa tua percepção enquanto professora, de entender que esse processo de representar com desenho ou de outras maneiras... começou a aparecer a partir da formação do PNAIC? Ou tu já tinhas essa percepção antes? P2.6: Eu tinha essa percepção, mas a formação me deu a segurança de trabalhar sem medo. E poder aceitar. (WEBER, 2018, p. 114)

Entendemos que quando um professor reconhece que consegue criar a partir do que experimentou na formação, reafirma sua importância e indica que é possível se apropriar de conhecimentos que Ihe permitem extrapolar o conhecido, numa postura reflexiva desejável para a construção de sua autonomia docente. Mas, para que o professor tenha autonomia para criar, é preciso que ele domine também o conhecimento específico de matemática que vai ensinar e tenha compreensão de como a criança aprende. Encontramos nos estudos de Justo e Dorneles (2012, p. 92), fazendo uma referência aos estudos de Shumann, uma indicação que corrobora nossa compreensão quando afirmam que o professor que ensina matemática necessita de conhecimentos do conteúdo matemático e de sua didática. E é sobre esses conhecimentos que trataremos no próximo tópico.

\section{APRENDIZAGENS A PARTIR DA FORMAÇÃO}

Como dito anteriormente, compreendemos que 0 conhecimento matemático e didático do professor são condições indiscutíveis para que o professor possa construir uma prática de ensino adequada. Esse domínio é fundamental para que o professor tenha autonomia intelectual para produzir e planejar as situações didáticas que irá propor aos seus alunos e, assim, percebe-se a prática reflexiva como um caminho promissor na formação de professores. Ainda segundo Justo e Dorneles (2012, p. 92), 0 professor precisa ter um sentimento de confiança em relação à matemática para que possa ajudar seus alunos a pensarem matematicamente e encontrarem caminhos para chegar a determinadas soluções. 
Nessa pesquisa, algumas professoras manifestaram suas mudanças pessoais, indicando que os estudos e as atividades práticas realizadas na formação do PNAIC possibilitaram aprendizagens e reflexões sobre o conhecimento matemático de que dispunham a priori e a partir do curso. É o que podemos conferir nas declarações abaixo, nas quais elas afirmam que passaram a ver o conteúdo de maneira diferente e isso Ihes permitiu trabalhar de outra forma, diferente do que faziam ou de como aprenderam:

[...] Da compreensão daquele conteúdo que hoje eu o vejo diferente. A partir do momento que eu consigo vê-lo diferente, eu consigo explicar diferente. Isso foi bem forte. Quando a gente faz essas formações, a gente acaba entendendo conteúdo. Ah! A questão [...] do vai 1. Que a gente entende porque que é 0 vai 1 , os reagrupamentos com reserva, tanto na adição quanto na subtração. (P3.3) (WEBER, 2018, p. 116)

Nas falas da professora P3.3 podemos verificar que conceitos que nos parecem elementares, como a base 10, que sustenta nosso Sistema de Numeração Decimal, não é exatamente uma obviedade para todos. A formação do PNAIC não tinha o objetivo direto de ensinar este conteúdo ou outros citados, mas, ao estudar e realizar atividades didáticas de como ensiná-los, alguns professores admitiram ter melhorado sua compreensão sobre eles, tornando-se autônomos para criar situações de ensino que atendiam as necessidades de aprendizagem dos alunos de suas turmas, como podemos observar nos excertos seguintes:

Acho que aprendi o entendimento sobre numeração e sistema de numeração decimal. A formadora batia muito nisso. A compreensão do que era uma dezena, a partir da base 10. A questão das medidas, a gente fazia bastante atividade sobre medidas com garrafa, com copinhos, com as medidas da sala, medir em passos. Então medidas e SND foram coisas que a gente trabalhou bastante, foi um ano bem intenso disso. (P1.1) (WEBER, 2018, p. 117)

As contribuições da formação do PNAIC aparecem positivamente nas falas analisadas até aqui, indicando que as professoras reconhecem efeitos dos estudos, reflexões e socialização de práticas para a constituição de sua docência e relatam algumas transformações ocorridas.

Nas falas das professoras P2.6 e P3.1, é possível perceber que essa relação positiva com a matemática veio permeada pelo prazer que passaram a sentir ao ensinar o que antes Ihes causava até um certo sofrimento.

Pra mim, desmistificou. Hoje eu amo ensinar matemática [...] Eu explico para os meus alunos que a matemática está em tudo. Em qualquer coisa que a gente fizer, a matemática está envolvida. Hoje eu ensino matemática brincando. Eu curto ensinar matemática! Antes me parecia mais desgastante, mais sofrido. (P2.6)

Mas na matemática, a formação foi que me tirou o medo. Adoro gráficos, hoje em dia! Adooooro! (risos) Com os alunos eu faço gráfico de tudo, até da frequência com que eles vão ao banheiro. (P3.1) (WEBER, 2018, p. 116)

Porém, essas aprendizagens relatadas só fazem sentido se produzirem alguma transformação nas práticas de ensino, de modo a contribuir efetivamente para a aprendizagem das crianças em fase 
de alfabetização. Neste sentido, apresentamos algumas manifestações que representam tentativas de mudanças por parte das professoras, trabalhando com conteúdos que antes thes pareciam complicados, ou propondo uma nova abordagem metodológica, num movimento de transformação, com a desconstrução e a reconstrução de saberes.

Antigamente eu ensinava o número pelo número, agora eu vou instigando para eles entenderem que o número tem uma função social: está num contexto e serve para alguma coisa. (P3.1)

Ainda tenho dificuldade e insegurança, mas alguns conteúdos eu até já consigo trabalhar melhor, porque desconstruir o que já estava consolidado é, e está sendo 0 maior desafio. Dentro dos eixos, hoje eu trabalho melhor o Sistema de Numeração Decimal e Grandezas e medidas. (P3.4)

Hoje, no $3^{\circ}$ ano, eu estou trabalhando grandezas e medidas e medidas padrões, e tudo na prática primeiro. As crianças tem que se envolver, fazer a atividade mesmo... Parece pra elas que estão brincando, mas elas estão aprendendo matemática. Então a matemática pra mim hoje, ela é primeiro a prática e depois a gente vai pra sistematização. (P3.4) (WEBER, 2018, p. 117-118)

Quando as professoras P3.1 e P3.4 conseguem perceber que antes trabalhavam de um jeito e então passaram a trabalhar de outro, manifestam um estado de consciência sobre o próprio processo de formação e transformação.

Compreendemos, assim, que o professor se torna autônomo quando é capaz de utilizar seus conhecimentos pedagógicos, com uma postura ética, para resolver os problemas do seu cotidiano buscando, criando e/ou adaptando soluções que atendam seus objetivos. A partir desse contexto é possível confirmar nosso pressuposto de que uma postura autônoma facilita a efetivação de transformações no fazer pedagógico, desde que o professor realmente domine os conhecimentos específicos do conteúdo a ser ensinado, bem como os da sua profissão docente e tenha desenvolvido certa consciência sobre seu saber-fazer.

Pesquisadoras como Reges e Barreto (2005) e Lima (2007) apontam que no caso dos conteúdos de matemática, professores pedagogos, por vezes, não têm uma relação muito tranquila com a disciplina. Porém, observamos que os cursos de formação continuada têm contribuído para melhorar essas relações ajudando muitos professores a viverem novas experiências que promovem transformações em sua autoidentidade (DUBAR, 1997), ou seja, sobre a percepção de si mesmo em relação aos conhecimentos matemáticos e sua capacidade para lidar com eles, melhorando assim sua relação pessoal com o próprio conteúdo e com as formas de ensinar. Vejamos algumas declarações que demonstram como as aprendizagens do curso ajudaram alguns professores a ressignificar seus conhecimentos específicos de matemática, como a base 10 do Sistema de Numeração Decimal, 0 valor posicional dos algarismos e outros:

0 principal foi a questão da troca. Porque na escola a gente aprendeu que empresta o número. Então a troca, separar 10, distribuir 1 real em 10 moedinhas, seja usar canudos para fazer as trocas de dezena e unidade... isso ficou mais tranquilo de ensinar. A gente aprendeu (quando aluna) que empresta, mas empresta e não devolve! IsSo o PNAIC deixou muito claro porque a gente teve a experiência de como trabalhar e entender porque que troca. A gente pode dizer que a formação do PNAIC deu uma 
condição melhor de entender que não era o empresta, que eram trocas que eram feitas e a experiência de fazer as atividades na formação gera segurança para fazer na sala com os alunos! (P1.1) (WEBER, 2018, p. 120)

Percebemos que as mudanças nas atividades dos professores constituem-se de um processo que exige conhecimento, dedicação e tempo. Essas declarações marcam um movimento de transformação iniciado a partir de experiências vividas no curso, mas que precisa de tempo para ser consolidada dentro das escolas. É o que afirma Nacaratto (2000) citada por Passos (2006): É preciso tempo para aprofundar um conteúdo; elaborar, desenvolver e analisar um projeto; crescer, aprender e mudar.

\section{RECURSOS, MATERIAIS E ESTRATÉGIAS}

Ao falar sobre os Direitos de Aprendizagem (conceito trazido na formação do PNAIC, com relação aos conhecimentos necessários a serem ensinados às crianças), Teles (2014) explica a importância da incorporação de recursos como jogos, materiais manipuláveis e literatura infantil como estratégias de ensino indispensáveis no ciclo de alfabetização:

No Ciclo de Alfabetização, as crianças precisam ser ativas na sala de aula: manipular objetos; construir e desconstruir sequências; desenhar, medir, comparar, classificar e modificar sequências estabelecidas por padrões. Essas atividades são amplamente mobilizadas pelo uso do próprio corpo como referência para contagens e medições, pelo uso de jogos, materiais diversos e livros de literatura já distribuídos pelo MEC e presentes nas escolas (TELES, 2014, p. 45).

Constatamos, então, que os conhecimentos e a linguagem matemática estão presentes em diferentes contextos sociais e se materializam em diferentes situações do cotidiano. Por isso, a formação do PNAIC propôs também um estudo sobre alguns recursos, estratégias e materiais que podem contribuir com o professor na construção de uma prática mais atraente e significativa para ensinar matemática para crianças. Dentre essas questões, apresentamos algumas percepções sobre atividades lúdicas, materiais manipuláveis e literatura infantil como elementos de transformação para quem as usa no cotidiano.

Durante a formação do PNAIC, em 2014, a discussão sobre a estrutura lúdica da atividade matemática esteve muito presente, atendendo um dos pressupostos da formação de acordo com a introdução do caderno de apresentação:

Este caderno explicita dois pressupostos fundamentais para o trabalho pedagógico com as crianças dessa faixa etária: o papel do lúdico e do brincar e a necessidade de aproximação ao universo da criança, respeitando seus modos de pensar e sua lógica no processo da construção dos conhecimentos (BRASIL, 2014, p. 9).

Nessa pesquisa verificamos que 40 dos 94 participantes que responderam o questionário inicial disseram planejar e desenvolver atividades lúdicas com muita frequência, enquanto 26 disseram realizar sempre ou quase sempre e 25 admitem fazê-lo com pouca frequência e citaram como exemplos: jogos, brincadeiras e músicas.

Embora essa constatação demonstre um quadro bastante otimista em relação aos pressupostos da formação, faz-se necessário compreender quais são as nuances dessa postura positiva dos 
professores em relação à ludicidade como estratégia possível para ensinar matemática. Os professores que realizam poucas atividades lúdicas visando essa finalidade alegaram como justificativas: 1) Falta de tempo para preparar tais atividades; 2) Falta de condições pela organização ou 0 grande número de alunos na turma; 3) São tradicionais e não se sentem à vontade para tal, acham que são menos importantes que os conteúdos (referindo-se à quantidade de conteúdos que precisam ensinar e aos conteúdos de Língua Portuguesa-Alfabetização) e 4) Reconhecem a importância de tais atividades, mas simplesmente não as realizam.

Para os professores que pareciam já ter encontrado seu espaço-tempo para o desenvolvimento dessas atividades e afirmaram realizá-las com muita frequência ou quase sempre, as justificativas aparecem relacionadas mais às condições das crianças do que à ação do professor, como se esses professores priorizassem as necessidades do aluno, ao contrário do que acontece com as justificativas para a não realização destas atividades, que estão mais relacionadas às suas condições de trabalho. Os motivos pelos quais eles justificaram a realização de atividades lúdicas para ensinar Matemática são: 1) Facilitam a compreensão e a aprendizagem dos conteúdos. 2) São atividades prazerosas e motivam as crianças. 3) São necessárias em função da faixa etária das crianças. 4) Proporcionam maior participação e interação entre as crianças. 5) Oportunizam a inclusão das crianças que não estão no mesmo nível de aprendizagem das demais.

Sobre a potencialidade pedagógica de atividades lúdicas, como os jogos, por exemplo, os cadernos de estudo trazem o seguinte pressuposto:

Os estudos sobre as relações entre jogos e aprendizagem Matemática têm apontado para 0 grande potencial educativo das atividades lúdicas, quando as crianças podem agir de maneira mais autônoma e confrontar diferentes representações acerca do conhecimento matemático (MUNIZ, 2014, p. 66).

E apontam para a importante tarefa do professor nesse processo de ensino e aprendizagem:

De acordo com nossos pressupostos, compreendemos que o jogo em sala de aula não pode ser visto como um mero passatempo. Por esse motivo, com vistas a auxiliar 0 trabalho pedagógico e ampliar as potencialidades do uso de jogos no desenvolvimento dos conceitos matemáticos, uma série de considerações são necessárias, em particular as que tratam do papel do professor (SOBCZAK; ROLKOUSKI; MACCARINI, 2014, p. 5).

Nesse sentido, o professor precisa ter clareza sobre os procedimentos da atividade ou do jogo, seus objetivos com relação ao conteúdo e o planejamento de suas ações para a interação com os alunos. Segundo Grando (2000):

um mesmo jogo pode ser utilizado, num determinado contexto, como construtor de conceitos e, num outro contexto, como aplicador ou fixador de conceitos. Cabe ao professor determinar o objetivo de sua ação, pela escolha e determinação do momento apropriado para o jogo. Neste sentido, o jogo transposto para o ensino passa a ser definido como jogo pedagógico (GRANDO, 2000, p. 19). 
Nesse tipo de atividade a intenção do professor precisa estar clara para que ele possa, inclusive, perceber quando a atividade lúdica ou o jogo realmente contribuem ou não para que seus objetivos pedagógicos sejam atingidos.

Além do seu aspecto recreativo, o jogo é uma atividade pedagógica que, se utilizado nas aulas de matemática, possibilita colocar 0 aluno em movimento de resolução de problemas (GRANDO; PELLATIERI, 2016) e de interação com 0 outro. Para Grando e Pellatieri (2016) 0 jogo é um problema dinâmico que depende da ação do adversário e a motivação de vencer gera a necessidade do domínio de diversas formas de resolução dos problemas surgidos durante o jogo. Elas afirmam que as diferentes formas de se expressar no jogo, pelos registros das jogadas e resolução de problemas, evidenciam processos de letramento matemático.

Sobre os registros a partir de jogos Sobczak, Rolkouski e Maccarini $(2014$, p. 8) sugerem que:

0 professor pode e deve incentivar os registros escritos para a marcação dos pontos. Com vistas a ampliar as possibilidades de aprendizagem, poderá sugerir diferentes maneiras. [...] poderá questionar os alunos sobre qual registro permite uma contagem mais rápida e 0 porquê. [...] 0 professor poderá ainda incentivar a utilização de algarismos ou não, de acordo com a faixa etária e 0 jogo utilizado. Isso porque a utilização dos algarismos nem sempre é a melhor opção para os jogos.

Além de todas as possibilidades de aprendizagem que a criança pode acessar através de jogos e brincadeiras, os registros ajudam na sistematização de conceitos e podem proporcionar a criação e a resolução de situações problema, que não necessariamente precisam ter o formato escolarizado. Podem ser desafios lançados ao grupo ou a um aluno específico, dependendo novamente da lógica pedagógica do professor e de seus objetivos.

Além de um jogo propriamente dito, estruturado com regras, uma atividade com material manipulável também pode acontecer de forma lúdica, como declara a professora P3.4 com relação ao uso de material dourado ou fichas coloridas para a realização de contagens:

Os estudantes apreciam os jogos, os desafios matemáticos. Montar o número com o material dourado para o colega adivinhar, fichas coloridas, contagem com as mãos, etc. 0 meu objetivo é observar como eles (os alunos) estão pensando e compreendendo 0 que estou ensinando e a cada ano e momento sempre aprendo e é aí que percebo 0 avanço nas minhas estratégias de ensino. (P3.4) (WEBER, 2018, p. 132)

Nessa declaração, a professora P3.4 acaba fazendo uma autoavaliação, quando diz que percebe 0 avanço de suas estratégias de ensino. Essa consciência de seu próprio avanço confirma novamente como o professor vai transformando a si e ao seu saber-fazer na própria prática, como afirma Tardif (2014). Mas, além de possibilitarem um caráter lúdico ao trabalho pedagógico, os materiais manipuláveis podem exercer uma importante função na aprendizagem de conteúdos matemáticos, enquanto instrumentos que facilitam a compreensão de conceitos e/ou operações, contribuindo para a construção do pensamento abstrato. No entanto,

0 professor precisa ter em mente que 0 material não pode provocar indução ao erro nem a inversão didática, que acontece quando 0 aluno abstrai o material em si e não o conteúdo/conceito pretendido. Geralmente, a expectativa da utilização 
de recursos dessa natureza por parte de professores está na esperança de que as dificuldades de ensino possam ser amenizadas pelo suporte da materialidade. Contudo, a simples manipulação de objetos não leva à compreensão dos conteúdos, podendo até mesmo causar problemas com a conceituação. Não é incomum que se acredite que apenas manipulando um ábaco ou outro material manipulável 0 aluno está aprendendo a contar ou a fazer contas. De fato, 0 uso de um material manipulável somente é eficiente se utilizado adequadamente. (BRASIL, 2015, p. 10)

Para Aragão e Vidigal (2012) o material manipulável, ou manipulativo, é recurso aliado do ensino e contribui para a construção de significados, gerando possibilidades de representação de conceitos e procedimentos. Mas deve ser abandonado pelo aluno à medida que ele aprende e as ideias ganham sentido. Por isso, esses equipamentos didáticos precisam estar associados a atividades reflexivas e registros de aprendizagens.

Lorenzato (2010) afirma que os materiais são facilitadores da aprendizagem e alerta que, quando se destinam aos primeiros anos do ensino fundamental, devem estar fortemente centrados no apelo tátil e visual e visar mais diretamente a ampliação de conceitos, a descoberta de propriedades, a percepção da necessidade do emprego de termos e símbolos, a compreensão de algoritmos, enfim, os objetivos matemáticos (LORENZATO, 2010, p. 9).

Nessa lógica percebemos que a professora P3.3 manifesta que aprendeu a trabalhar adição e subtração com o material dourado e, por ter compreendido como ocorrem as trocas (de agrupamentos e desagrupamentos), sente-se segura para utilizar esta estratégia:

0 manuseio do material dourado que a gente acabou aprendendo técnicas de como trabalhar adição e subtração... isso é uma coisa que eu continuo seguindo em todas as turmas que eu tenho trabalhado. Porque a partir do momento que tu dominas a troca, a estratégia de como trocar e fazer a compreensão, eu continuo seguindo. (P3.3) (WEBER, 2018, p. 134)

Salientamos que saber as funções e as possibilidades de uso de cada material é de fundamental importância para a prática do professor. Segundo Silveira (2016), o material dourado, por exemplo, é um importante recurso para a representação da base numérica decimal, enquanto ábacos são bons recursos para a compreensão do valor posicional do sistema de numeração e a realização de operações numéricas.

Esse autor alerta que é importante que o professor conheça e reconheça as possibilidades de exploração de cada material, a fim de que possa fazer propostas adequadas que contribuam para a aprendizagem das crianças.

Ainda nesse sentido, Passos (2010, p. 81) alerta:

Qualquer material pode servir para apresentar situações nas quais os alunos enfrentam relações entre os objetos que poderão fazê-los refletir, conjecturar, formular soluções, fazer novas perguntas, descobrir estruturas. Entretanto, os conceitos matemáticos que eles devem construir, com a ajuda do professor, não estão em nenhum dos materiais de forma que possam ser abstraídos deles empiricamente. 
Livros de literatura infantil também foram considerados pelas professoras, bons recursos para 0 ensino de matemática. Dentre as ações do programa, diversos acervos de livros de literatura infantil foram enviados para as salas de aula de turmas de alfabetização de todo o Brasil. Havia muitos livros relacionados aos conceitos matemáticos como medidas, contagens, estimativas, probabilidades e outros. Esses livros apresentam de maneira lúdica e literária, como a matemática está presente na cultura popular, em parlendas e brincadeiras infantis. Desse modo, constituem um recurso importante também para 0 ensino de Matemática.

\section{ESTRUTURA METODOLÓGICA DA FORMAÇÃO}

Outras questões emergiram das falas das professoras entrevistadas, não sendo diretamente contribuições que pudessem influenciar a transformação de suas práticas pedagógicas, mas são questões importantes sobre a constituição da própria formação oferecida no que diz respeito à sua organização metodológica, a periodicidade sistemática dos encontros, a qualidade do material de estudo e até mesmo 0 apoio do formador que planeja o curso e faz a mediação necessária para que 0 curso possa realmente estar articulado às necessidades dos professores participantes.

Percebemos, nas manifestações de professores que participaram da formação, que os encontros organizados sistematicamente de forma mensal proporcionavam-Ihes certa satisfação no sentido de sentirem-se mais amparados e preparados para sua ação docente pelo fato de vivenciarem as atividades práticas e terem a oportunidade de refletirem sobre elas. Romanatto (2000, p. 157) explica que quando os professores vivenciam experiências práticas como se fossem alunos, fazem analogias com seus alunos reais e, durante essas práticas, as análises e discussões fazem mais sentido. Eles demonstraram também que valorizam os encontros de formação como oportunidade de aprender alguma coisa além da teoria e poder pensar sobre o que serve ou não para sua turma.

Ainda, segundo Romanatto (2000) durante a reflexão em conjunto com os pares, pontos de vista podem ser incorporados, confrontados e discutidos. Novos elementos podem surgir. Outras crenças, concepções e conhecimentos podem ser acrescentados à reflexão inicial.

Outro procedimento previsto na organização metodológica da formação do PNAIC era a realização de atividades em serviço, à distância. Na Rede Municipal de Ensino de Florianópolis as atividades eram solicitadas de acordo com o tema estudado no encontro e os relatos advindos da realização dessas atividades com as crianças eram apresentados no encontro seguinte, tornando-se base para reflexões coletivas.

A professora P3.3 relata sua percepção sobre como as atividades solicitadas tinham um caráter formativo, ajudando-a a avaliar sua própria prática:

Nas formações tu tens que pensar um planejamento, mas não um planejamento para o papel, era um planejamento voltado pra tua turma. E depois do planejamento tu vias aquilo que dava certo, aquilo que não dava e isso faz com tu avalies e faz com que tu cresças... Ver o que vale a pena investir, 0 que não vale a pena investir. Isso vai ampliando a tua prática. (P3.3) (WEBER, 2018, p. 143)

Essa constatação nos remete à necessidade de repensar a organização de formações oferecidas aos professores, pois, para que possíveis mudanças ocorram na constituição docente se consolidem, precisam refletir nas salas de aulas, com os alunos. É fundamental que essas transformações, 
com o tempo, sejam incorporadas nas rotinas dos professores, modificando seu habitus profissional (PERRENOUD, 2001b).

\section{CONDIÇÕES DE TRABALHO}

Os aspectos sobre as condições de trabalho que emergiram das entrevistas não tinham a conotação de contribuição para a prática pedagógica e, sim, de dificuldades encontradas pelos professores para promoverem algumas transformações consideradas necessárias (por eles mesmos) para a qualificação de suas práticas docentes. Consideramos importante citar essas condições desfavoráveis porque, sendo apresentadas pelos professores, indicam que são questões que precisam ser consideradas pelos formadores como temas de reflexão e discussão, passíveis de ressignificações e, quiçá, de reformulações de atitudes frente às dificuldades inerentes ao fazer pedagógico, principalmente se considerarmos uma postura política de enfrentamento às condições impostas por governos e políticas públicas que regem a educação no país.

Silveira e Caldeira (2012) constataram que existem obstáculos e resistências por parte dos professores quando esses se defrontam com novas propostas de trabalho, diferentes das que já fazem parte de suas práticas consolidadas. São obstáculos de diferentes naturezas, e dizem respeito às relações que estabelecem com a escola, com o trabalho, com o currículo, com as famílias dos alunos e com o conhecimento matemático ou os procedimentos metodológicos para trabalhar com ele. Dentre os aspectos observados por esses pesquisadores, aparecem questões como o tempo que o professor investe no preparo de sua aula e no desenvolvimento do conteúdo, que é uma questão que também emergiu nas falas das professoras participantes dessa pesquisa.

0 tempo disponível (ou a falta dele) para preparar a aula surgiu como tema relevante nas entrevistas, como uma justificativa para a não implementação das transformações (até avaliadas como necessárias ou importantes pelas professoras) que não conseguem colocar em prática.

0 acesso aos materiais necessários ao trabalho em sala de aula também foi levantado como uma condição que facilita ou dificulta a realização de alterações na ação pedagógica dos professores. Sendo essa diretamente relacionada à questão do tempo, o professor acaba por utilizar o que lhe é mais acessível em sala de aula.

Com base em declarações dessas professoras, é possível compreender que quando a escola oferece uma estrutura adequada de disponibilização de recursos materiais, 0 acesso dos professores a eles fica facilitado. Numa pesquisa sobre os impactos de materiais curriculares nas práticas de professores que ensinam matemática nos anos iniciais, Pacheco e Pires (2015) constataram que as ações dos professores são significativamente influenciadas pelos recursos disponíveis, como: materiais manipuláveis, livros didáticos ou outros materiais curriculares. Mas esses elementos só ganham significado na ação do professor, como destacam Pacheco e Pires (2015): "Entretanto, vale destacar que os materiais manipulativos podem ser boas ferramentas desde que estejam acompanhados de intenções e propostas reflexivas. 0 material manipulativo por si só não garante aprendizagem" (PACHECO; PIRES, 2015, p. 238).

Sendo assim, fica o registro desses aspectos levantados nesta investigação: tempo disponível e material acessível fazem parte das condições de trabalho necessárias para que os professores que ensinam matemática em classes de alfabetização implementem transformações em suas práticas pedagógicas. 


\section{CONSIDERAÇÕES FINAIS}

Neste artigo, que representa um recorte da pesquisa realizada, podemos identificar que a formação continuada do PNAIC na área de Alfabetização Matemática trouxe importantes contribuições para muitos professores da rede municipal de ensino de Florianópolis, que são valorizadas por estes sujeitos como significativos para a qualificação de sua prática, tais como: aprendizagem de conceitos e procedimentos relacionados à alfabetização matemática e ao uso de materiais manipuláveis, a legitimação de práticas de atividades lúdicas como estratégias de ensino e o desenvolvimento de atitudes autônomas. Essa constatação aponta para a necessidade de manutenção desse tipo de estratégia utilizada na formação continuada, legitimando esse espaço e tempo de reflexão sobre a prática como uma possibilidade de qualificação profissional.

Compreendemos que as transformações nas práticas pedagógicas de professores não acontecem radicalmente de um ano para outro, simplesmente por terem participado de uma formação específica. Num contexto educacional existem muitos aspectos envolvidos, desde a subjetividade dos professores que vão se constituindo docentes durante a experiência até o sistema educacional do país, perpassando inúmeras variáveis. Mas fica evidente 0 potencial dos cursos de formação continuada como contribuições importantes nos processos de transformação das práticas de ensino, em prol da qualificação da educação em classes de alfabetização. 0 resultado dessa pesquisa indica que as possíveis mudanças elencadas ao longo deste texto dependem também das condições materiais e imateriais que estão além desses profissionais, nos contextos escolares, nas articulações pedagógicas dos projetos das unidades educativas, nas relações com as secretarias de educação, ou a comunidade escolar, nas possibilidades de acesso ao conhecimento científico e também no desejo pessoal de cada docente.

\section{REFERÊNCIAS}

ALARCÃO, Isabel. Professores reflexivos em uma escola reflexiva. 8. ed. Cortez, São Paulo, 2011.

ARAGÃO, Heliete Meira C.A.; VIDIGAL, Sônia Maria Pereira. Materiais manipulativos para 0 ensino de sistema de numeração decimal. (SMOLE, Kátia Stocco; DINIZ, Maria Ignes (Org.). Coleção Mathemoteca). Edições Mathema, São Paulo, 2012.

BRASIL. Ministério da Educação. Secretaria da Educação Básica. Pacto Nacional pela Alfabetização na Idade Certa: Caderno de Apresentação. Brasília: MEC/SEB, 2014.

Ministério da Educação. Secretaria da Educação Básica. Pacto Nacional pela Alfabetização na Idade Certa: Organização do trabalho pedagógico. Brasília: MEC/SEB, 2015.

Ministério da Educação. Secretaria da Educação Básica. Pacto Nacional pela Alfabetização na Idade Certa: Documento orientador. Brasília: MEC/SEB, 2017.

CURI, Edda. Análise de propostas presentes no material da Matemática do PEC-Universitário, à luz de resultados de investigações e teorias sobre formação de professores. In: NACARATO, Adair Mendes; PAIVA, Maria Auxiliadora Vilela. A formação do professor que ensina matemática: perspectivas e pesquisas. 3. ed., Ed. Autêntica, Belo Horizonte, MG, 2013. 
DUBAR, Claude. A socialização: construção das identidades sociais e profissionais. Tradução: BOTELHO, Anette P. R. e LAMAS, Estela P. R. Porto editora, Portugal, 1997.

FREIRE, Paulo. Pedagogia da autonomia. Paz e Terra. São Paulo, 1996.

GIL, Antônio Carlos. Como elaborar projetos de pesquisa. 5.ed., Atlas, São Paulo, 2010.

GRANDO, Regina Célia. 0 conhecimento matemático e $\mathbf{0}$ uso de jogos na sala de aula. Tese de doutorado. UNICAMP, Campinas, SP, 2000. Disponível em http://repositorio.unicamp. br/handle/REPOSIP/251334. Acesso em: 03 jan. 18.

GRAND0, Regina Célia; PELLATIERI, Mariana. Práticas de letramento matemático escolar no ciclo de alfabetização: jogo e resolução de problemas. In: SILVEIRA, Everaldo da et al. (Org.). Alfabetização na perspectiva do letramento: letras e números nas práticas sociais. UFSC/CED/NUP, Florianópolis, 2016, p. 241-255.

JUSTO, Jutta Conelia R.; DORNELES, Beatriz Vargas. Formação continuada em matemática de professores polivaIentes: dois estudos sobre resolução de problemas aditivos. REVEMAT, n. 1, v. 7, 2012, p. 78-96.

LORENZATO, Sérgio (Org.). Laboratório de ensino de matemática e materiais didáticos. In: 0 laboratório de ensino de matemática na formação de professores. Autores associados, Campinas, SP, 2010.

LIMA, Ivoneide Pinheiro. A matemática na formação do pedagogo: oficinas pedagógicas e a plataforma teleduc na elaboração dos conceitos. Tese (Doutorado em Educação) - Programa de Pós-Graduação em Educação, Faculdade de Educação da Universidade Federal do Ceará, Fortaleza-CE, 2007.

LUDKE, Menga; ANDRÉ, Marli E. D. A. Pesquisa em educação: abordagens qualitativas. EPU, São Paulo, 1986.

MONTEIRO, Dirce Charara; GIOVANNI, Luciana Maria. Formação Continuada de professores: o desafio metodológico. In: MARIN, Alda Junqueira et al. (Org.). Educação continuada: reflexões, alternativas. Papirus, São Paulo, 2000.

MUNIZ, Cristiano. Papéis do brincar e do jogar na Alfabetização Matemática. In BRASIL. Ministério da Educação. Secretaria da Educação Básica. Pacto Nacional pela Alfabetização na Idade Certa: Caderno de Apresentação. MEC/SEB, Brasília, 2014, p. 56-70.

NACARATO, Adair Mendes. A formação matemática das professoras das séries iniciais: a escrita de si como prática de formação. Revista Bolema, n. 37, v. 23, 2010, p. 905-930.

PACHECO, Débora Reis; PIRES Célia Maria Carolino. Impactos de materiais curriculares na prática do professor que ensina matemática nos anos iniciais. Revista REVEMAT, Florianópolis, SC, v. 10, n. 2, 2015, p. 227-242.

PASSOS, Carmen Lúcia. Materiais manipuláveis como recursos didáticos na formação de professores de matemática. In: LORENZATO, Sérgio (Org.). 0 laboratório de ensino de matemática na formação de professores. Autores associados, Campinas, SP, 2010, p. 77-92.

PERRENOUD, Philippe. 0 trabalho sobre 0 habitus na formação de professores: análise das práticas e tomada de consciência. In: PAQUAY, Leopold et al. (Org.) Formando professores profissionais: Quais estratégias? Quais competências? Ed. Artmed, Porto Alegre, RS, p 161-184, 2001. 
PIMENTA, Selma Garrido et al. Saberes pedagógicos e atividade docente. 7. ed., São Paulo, Ed. Cortez, 2009.

REGES, Maria Auricélia Gadelha e BARRETO, Marcília Chagas. Análise do desempenho de professores do II ciclo do Ensino Fundamental na resolução de problemas de adição e subtração: um estudo de caso. In Formação e Prática Docente: história, política e experiências pedagógicas. Fortaleza: UECE, 2005.

ROMANATTO, Mauro Carlos. Educação continuada no ensino de matemática. In: JUNQUEIRA, Aldo (org.) et al. Educação continuada: reflexões, alternativas. Papirus, São Paulo, SP, 2000, p. 145-160.

SILVA, Claudionor Renato da. Professores que vão ensinar matemática nos anos iniciais: educação matemática nos cursos de pedagogia. REVEMAT, v. 8, Ed especial, 2013, p. 117-133

SILVEIRA, Everaldo da. Materiais manipuláveis e alguns riscos que envolvem sua utilização. In: SILVEIRA, Everaldo da et al. (Org.). Alfabetização na perspectiva do letramento: letras e números nas práticas sociais. UFSC/CED/NUP, Florianópolis, 2016, p. 221-240.

SILVEIRA, Everaldo da; CALDEIRA, Ademir Donizeti. Modelagem na sala de aula: resistências e obstáculos. Bolema, Rio Claro (SP), v. 26, n. 43, ago. 2012, p. 1021-1047.

SOBCZAK, Anne Heloíse C. S.; ROLKOULSKI, Emerson; MACCARINI, Justina C. Motter. Apresentação. In: BRASIL. Ministério da Educação. Secretaria da Educação Básica. Pacto Nacional pela Alfabetização na Idade Certa: Jogos na alfabetização matemática. Brasília: MEC/SEB, 2014.

SZYMANSKI, Heloisa (Org.); ALMEIDA, Laurinda Ramalho; PRANDINI, Regina Célia A. Rego. A entrevista na pesquisa em educação: a prática reflexiva. Liber Livro Editora, Brasília, 2004.

TARDIF, Maurice. Saberes docentes e formação profissional. Tradução: PEREIRA, Francisco. 17. ed., Ed. Vozes, Petrópolis, RJ, 2014.

TAROZZI, Massimiliano. $\mathbf{0}$ que é Grounded theory?: metodologia de pesquisa e de teoria fundamentada nos dados. Ed. Vozes, Rio de Janeiro, 2011.

TELES, Rosinalda Aurora de Melo. Direitos e objetivos de aprendizagem e desenvolvimento: a Matemática como instrumento de formação e promoção humana. In: BRASIL. Ministério da Educação. Secretaria da Educação Básica. Pacto Nacional pela Alfabetização na Idade Certa: Caderno de Apresentação. MEC/SEB, Brasília, 2014, p. 38-55.

WEBER, Daniela Guse. Pacto Nacional pela Alfabetização na Idade Certa: Contribuições à prática pedagógica de professores que ensinam matemática em classes de alfabetização. Dissertação (Mestrado em Educação Científica e Tecnológica) - Programa de Pós-Graduação em Educação Científica e Tecnológica, Universidade Federal de Santa Catarina, Florianópolis-SC, 2018.

RECEBIDO EM: 31 mar. 2021

CONCLUÍDO EM: 30 jul. 2021 
